\title{
Subcellular localization, speciation and imaging of mercury during bacterial methylation process
}

\author{
MAUREEN LE BARS, SOPHIE BARROUILHET, \\ MATHILDE MONPERRUS, MARISOL GOÑI URRIZA, \\ EMMANUEL TESSIER AND MARIE-PIERRE ISAURE \\ Université de Pau et des Pays de l'Adour, E2S UPPA, CNRS, \\ MIRA, Institut des Sciences Analytiques et de Physico-chimie \\ pour l'Environnement et les matériaux, IPREM UMR5254 \\ Presenting Author: maureenlebars@gmail.com
}

Microbial $\mathrm{Hg}$ methylation is a key process in the $\mathrm{Hg}$ cycle occurring in soils, sediments and anoxic waters and controlling the neurotoxic methylmercury $\left(\mathrm{CH}_{3} \mathrm{Hg}\right)$ concentrations in aquatic environments [1]. Despite our improved understanding of the microbiological mediated $\mathrm{Hg}$ methylation in the environment and the identification of the involved bacteria (e.g. sulfate-reducing bacteria (SRB)) [2], the cellular mechanisms leading to $\mathrm{CH}_{3} \mathrm{Hg}$ remain not well understood. Because methylation extent seems to be controlled by cellular uptake [3], the assessment of the localization of mercury at the subcellular level is critical to provide mechanistic insights of such processes.

In this work, a kinetic study of $\mathrm{Hg}$ methylation was conducted with a model SRB strain, Pseudodesulfovibrio hydrargyri BerOc1, during 24 hours and for different mercury concentrations $(0.05 \mu \mathrm{M}$ to $5 \mu \mathrm{M})$. The quantification of $\mathrm{CH}_{3} \mathrm{Hg}$ and inorganic $\mathrm{Hg}$ in different subcellular fractions at different kinetic times was performed by GC-ICP-MS. We used Hg L3edge High energy Resolution X-ray Absorption Near Edge Structure (HR-XANES) spectroscopy to determine $\mathrm{Hg}$ ligands and coordination. Finally, cells were imaged by High resolution Scanning Transmission Electron Microscopy (HR-STEM) and Synchrotron Radiation based nanoscopic X-Ray Fluorescence (SR nano-XRF) during the $\mathrm{Hg}$ methylation to locate $\mathrm{Hg}$ and other metals during $\mathrm{Hg}$ methylation.

The results showed that $\mathrm{Hg}$ methylation reaction rate depended on $\mathrm{Hg}$ concentration, and that a saturation of the methylation process occurred. At the $\mathrm{Hg}$ concentrations tested, a maximal threshold value of intracellular $\mathrm{CH}_{3} \mathrm{Hg}$ was reached, explaining why $\mathrm{CH}_{3} \mathrm{Hg}$ is mainly found in the extracellular medium. On the other hand, intracellular inorganic $\mathrm{Hg}$ content increased during the incubation whatever the added $\mathrm{Hg}$ concentration. Tetra-coordinated $\mathrm{Hg}-\mathrm{S}$ species were identified as the dominant $\mathrm{Hg}$ species in the bacteria. Chemical imaging validated that $\mathrm{Hg}$ is both extracellular and intracellular. Interestingly, we observed a high heterogeneity between bacterial cells with $\mathrm{Hg}$ 'hyperaccumulating' cells and low accumulating cells. These outcomes open new perspectives for studying $\mathrm{Hg}$ methylation mechanisms at the cell level.

[1] Gustin MS. et al. (2020), Sci. Total Environ. 737, 139619

[2] Ranchou-Peyruse, M., et al. (2009), Geomicrobiol. J. 26(1), 1-8

[3] Hsu-Kim H.et al. (2013), Environ. Sci. Technol. 47(6), $2441-2456$ 